\title{
Antibacterial properties of silver nanoparticles synthesized by marine Ochrobactrum sp.
}

\author{
Roshmi Thomas ${ }^{1}$, Anju Janardhanan ${ }^{1}$, Rintu T. Varghese ${ }^{2}$, E.V. Soniya ${ }^{2}$, Jyothis \\ Mathew $^{1}$, E.K. Radhakrishnan ${ }^{1}$ \\ ${ }^{1}$ School of Biosciences, Mahatma Gandhi University, Kottayam, Kerala, India. \\ ${ }^{2}$ Plant Molecular Biology, Rajiv Gandhi Centre for Biotechnology, Thiruvananthapuram, Kerala, India.
}

Submitted: May 6, 2013; Approved: April 17, 2014.

\begin{abstract}
Metal nanoparticle synthesis is an interesting area in nanotechnology due to their remarkable optical, magnetic, electrical, catalytic and biomedical properties, but there needs to develop clean, non-toxic and environmental friendly methods for the synthesis and assembly of nanoparticles. Biological agents in the form of microbes have emerged up as efficient candidates for nanoparticle synthesis due to their extreme versatility to synthesize diverse nanoparticles with varying size and shape. In the present study, an eco favorable method for the biosynthesis of silver nanoparticles using marine bacterial isolate has been attempted. Very interestingly, molecular identification proved it as a strain of Ochrobactrum anhtropi. In addition, the isolate was found to have the potential to form silver nanoparticles intracellularly at room temperature within $24 \mathrm{~h}$. The biosynthesized silver nanoparticles were characterized by UV-Vis spectroscopy, transmission electron microscope (TEM) and scanning electron microscope (SEM). The UV-visible spectrum of the aqueous medium containing silver nanoparticles showed a peak at $450 \mathrm{~nm}$ corresponding to the plasmon absorbance of silver nanoparticles. The SEM and TEM micrographs revealed that the synthesized silver nanoparticles were spherical in shape with a size range from $38 \mathrm{~nm}-85 \mathrm{~nm}$. The silver nanoparticles synthesized by the isolate were also used to explore its antibacterial potential against pathogens like Salmonella typhi, Salmonella paratyphi, Vibrio cholerae and Staphylococcus aureus.
\end{abstract}

Key words: biosynthesis, silver nanoparticles, Ochrobactrum anhtropi, purification, antibacterial activity.

\section{Introduction}

Nanoparticles exhibit unique properties because of their size, distribution and morphology compared with larger particles of the bulk material. Thus, development of environmental friendly methods for the synthesis and assembly of nanoparticles is of considerable importance to explore their potential applications (Babu and Gunasekaran, 2009). Among the various methods of nanoparticle synthesis, biological methods are much promising because of its effectiveness, flexibility and environment friendly approach. Considering the diverse biological applications of silver nanoparticles(AgNPs), it is necessary to explore various biological systems for AgNPs production. Many mi- crobes including bacteria, yeast and fungi have been found to be capable of synthesizing silver nanoparticles. Among these microbes, bacterial systems are excellent option because they are easy to handle and can be manipulated genetically without much difficulty (Vaidhyanathan et al., 2010).

In microorganism mediated nanoparticle synthesis, the reduced metal in its elemental form can get accumulated either intracellularly or extracellularly (Ahmad et al., 2007; Kalimuthu et al., 2008; Saifuddin et al., 2009; Jain et al., 2011, Janardhanan et al., 2013). Studies on the biosynthesis of silver nanoparticles using the bacterium Pseudomonas stutzeri AG 259 isolated from silver mine demonstrated the intracellular synthesis of silver nano- 
particles with distinct size and morphology and was the first report on biosynthesis of AgNPs (Haefeli et al., 1984; Klaus et al., 1999). Later many bacterial species were studied for its ability to form nanoparticles. Bacillus licheniformis was shown to form AgNPs both intracellularly and extracellularly assisted by the enzyme nitrate reductase (Kalimuthu et al., 2008). Culture supernatants of Enterobacteriaceae (Klebsiella pneumoniae, Escherichia coli and Enterobacter cloacae) were found to form silver nanoparticles rapidly with a size range of 28.2 to $122 \mathrm{~nm}$ by reducing $\mathrm{Ag}+$ to $\mathrm{Ag} 0$ (Shahverdi et al., 2007). There are also several reports on the biosynthesis of AgNPs using bacteria like Bacillus subtilis (Kannan et al., 2011), Bacillus megaterium (Saravanan et al., 2011) and Acinetobacter sp. (Zaki et al., 2011), Bordetella sp.(Thomas et al., 2012a), Pseudomonas aeruginosa (Ramalingam et al., 2013).

Biologically produced metal nanoparticles, especially silver in a nanometric scale (less than $100 \mathrm{~nm}$ ) have received considerable application as antimicrobials, therapeutics and in biomolecular detection and catalysis (Christopher et al., 2011; Elechiguerra et al., 2005; Sadhasivam et al., 2010; Shrivastava et al., 2009; Wei et al., 2008). This is due to their well-developed surface which provides maximum contact with the environment (Krutyakov et al., 2008). Antimicrobial activity of silver nanoparicles against medically important pathogenic microorganisms such as Bacillus subtilis, Enterococcus faecalis, Escherichia coli, Salmonella typhimurium and Candida albicans were reported (Sadhasivam et al., 2010). Extracellular silver nanoparticles synthesized using Bacillus flexus were proved to have antibacterial effect on clinically isolated multidrug resistant (MDR) E. coli, B. subtilis, S. pyogenes and $P$. aeruginosa (Priyadarshini et al., 2013). Also silver nanoparticles generated extracellularly by Bacillis megaterium(NCIM 2326) were found to be effective against multi drug resistant clinical pathogens like S.pneumoniae and S.typhi (Saravanan et al., 2011). Furthermore, methicillin-resistant Staphylococcus aureus, methicillin-resistant Staphylococcus epidermidis and Streptococcus pyogenes were found to be susceptible to silver nanoparticles with size ranges from 160-180 nm (Nanda and Saravanan, 2009).

Thus the studies on antimicrobial activity of AgNPs generated by diverse microorganisms are of considerable clinical significance.

Although silver nanoparticle formation by various microorganisms is well known, the potential of marine microbes for this property is least explored. In the present study, a bacterial isolate from marine water collected from Calicut beach was used for the synthesis of silver nanoparticles. Very interestingly, the molecular identification proved the isolate (CB2) as species of Ocrobactrum anthropi and biosynthesis of AgNPs using this marine isolate is least investigated. Also the biosynthesized AgNPs showed promising antibacterial activity against medically important pathogenic bacteria (Salmonella typhi, Salmonella paratyphi, Vibrio cholerae and Staphylococcus aureus). Thus this study highlights the importance of exploring diverse microbial communities for nanoparticle synthesizing properties and their potential as nanomedicine to manage pathogenic microorganisms.

\section{Materials and Methods}

\section{Isolation of metal resistant bacteria}

Seawater samples were collected from Calicut beach, Kerala, India. Samples were serially diluted in sterile $0.8 \%$ $\mathrm{NaCl}$ and were plated onto Marine agar (ZoBell Marine agar media - Peptone $5 \mathrm{~g}$, Yeast extract $1 \mathrm{~g}, \mathrm{FePO}_{4} .4 \mathrm{H}_{2} \mathrm{O}$ $0.01 \mathrm{~g}$, Agar $15 \mathrm{~g}$, Aged sea water $750 \mathrm{~mL}$, and distilled water $250 \mathrm{~mL} \mathrm{pH} \mathrm{7.5)} \mathrm{and} \mathrm{incubated} \mathrm{at} \mathrm{room} \mathrm{temperature} \mathrm{for}$ $48 \mathrm{~h}$. The colonies obtained were further inoculated on marine agar supplemented with $1-20 \mathrm{mM}$ concentrations of filter sterilized $\mathrm{AgNO}_{3}$ and incubated at room temperature for $48 \mathrm{~h}$ for the screening of $\mathrm{Ag}$ resistant bacterial strains. After the incubation period, the resistant colonies formed were sub cultured and from this, a colony named as CB2 was randomly selected for nanoparticle synthesizing studies.

\section{Molecular identification}

Genomic DNA isolation of the selected isolate was conducted as per the method described by Ausubel et al. (1995). The isolates were cultured overnight in LuriaBertani broth and the cells were collected by centrifugation. The cells were then resuspended in $567 \mu \mathrm{L}$ of TE buffer followed by lysis using $30 \mu \mathrm{L}$ of $10 \%$ SDS and $3 \mu \mathrm{L}$ of $20 \mathrm{mg} / \mathrm{mL}$ protienase $\mathrm{K}$. The mixture was then incubated for $1 \mathrm{~h}$ at $37^{\circ} \mathrm{C}$. After which the lysate was mixed thoroughly with $100 \mu \mathrm{L}$ of $5 \mathrm{M}$ sodium chloride and $700 \mu \mathrm{L}$ chloroform: isoamyl alcohol (24:1) and this was centrifuged at 7,500 x $g$ for $10 \mathrm{~min}$. The aqueous layer was then transferred to a fresh tube and equal volume of isopropanol was added. This was then inverted several times and centrifuged again at 7,500 $\mathrm{x} g$ for $10 \mathrm{~min}$. The pellet was washed in $70 \%$ ethanol (v/v) and air dried at room temperature. The dried DNA pellet was resuspended in $100 \mu \mathrm{L}$ TE buffer and visualized on a $0.8 \%$ agarose gel $(\mathrm{w} / \mathrm{v})$. The isolated genomic DNA was used as template for PCR amplification of $16 \mathrm{~S}$ rDNA using the primers $27 \mathrm{~F}$ (5'-AgA gTTTgA TCM Tgg CTC-3') and 1525R (5'-AAg gAggTg WTC CAR CC-3') specific to $16 \mathrm{~S}$ rDNA(Chun and Goodfellow., 1995). The PCR was carried out in a total volume of $50 \mu \mathrm{L}$ containing $50 \mathrm{ng}$ of genomic DNA, 20 pmoles of each primer, 1.25 units of Taq DNA polymerase, $200 \mu \mathrm{M}$ of each dNTPs and 1X PCR buffer as components. The PCR was performed for 35 cycles in a Mycycler (Bio-Rad, USA) with the initial denaturation for 3 min at $94^{\circ} \mathrm{C}$, cyclic dena- 
turation for $30 \mathrm{~s}$ at $94{ }^{\circ} \mathrm{C}$, annealing for $30 \mathrm{~s}$ at $58^{\circ} \mathrm{C}$ and extension for $2 \mathrm{~min}$ at $72^{\circ} \mathrm{C}$ with a final extension of $7 \mathrm{~min}$ at $72{ }^{\circ} \mathrm{C}$. After the PCR, the reaction product was analyzed by agarose gel electrophoresis. The product was then gel purified and was further subjected to sequencing PCR using the Big Dye Terminator Sequence Reaction Ready Mix (Applied Biosystem). This was then subjected to sequencing using ABI 310 Genetic Analyser.

The sequence data was checked for similarity analysis with BLAST program (Zhang et al., 2000).

The phylogenetic analysis of the $16 \mathrm{~S}$ rDNA sequence of the isolates obtained in the study was also conducted with MEGA 5 using neighbor-joining method with 1,000 bootstrap replicates (Tamura et al., 2011).

\section{Synthesis of silver nanoparticles}

For nanoparticles synthesis studies, the bacterial isolate was freshly inoculated in an Erlenmeyer flask containing $100 \mathrm{~mL}$ marine broth. The flask was incubated in a rotating shaker at room temperature and agitated at $200 \mathrm{rpm}$ for $48 \mathrm{~h}$. After incubation, the biomass and supernatant were obtained by centrifugation at $12000 \mathrm{rpm}$ for $10 \mathrm{~min}$ and were used separately for the synthesis of silver nanoparticles. For the extracellular production of silver nanoparticles, supernatants were mixed with filter sterilized $\mathrm{AgNO}_{3}$ solution with a final concentration of $1 \mathrm{mM}$. For intracellular production; $2 \mathrm{~g}$ of bacterial wet biomasses were resuspended in $100 \mathrm{~mL}$ aqueous solution of $1 \mathrm{mM}$ $\mathrm{AgNO}_{3}$ in a $250 \mathrm{~mL}$ Erlenmeyer flask. Then the mixtures were kept on rotating shaker set at $200 \mathrm{rpm}$ for a period of $72 \mathrm{~h}$ at room temperature in light. The heat killed biomass and heat inactivated supernatant incubated with silver nitrate and silver nitrate solution alone were also maintained as control. The bioreduction of $\mathrm{Ag}+$ ions was monitored by changes in color. Also the optical characteristics of synthesized silver nanoparticles were measured using UV-visible spectrophotometer (Hitachi U5100) at 200-800 nm range with control as reference.

\section{Purification of silver nanoparticles from biomass}

For purification, the bacterial pellets were collected by centrifugation at $8,000 \mathrm{rpm}$ for $10 \mathrm{~min}$, resuspended in $0.9 \% \mathrm{NaCl}$ solution, and centrifuged again at $8,000 \mathrm{rpm}$ for $10 \mathrm{~min}$. The washing process was repeated three times to ensure removal of any undesirable materials. The pellets were then transferred to a test tube and were disrupted by ultrasound sonicator. This was then resuspended and centrifuged $(12,000 \mathrm{rpm})$ in a solution containing $0.5 \mathrm{M} \mathrm{NaCl}$ and $0.5 \mathrm{M}$ sucrose and was finally resuspended in $35 \mathrm{~mL}$ of complete salt solution $[\mathrm{NaCl}(17.5 \mathrm{~g} / \mathrm{L}), \mathrm{KCl}(0.74 \mathrm{~g} / \mathrm{L})$, $\mathrm{MgSO}_{4}-7 \mathrm{H}_{2} \mathrm{O}(12.3 \mathrm{~g} / \mathrm{L})$, Tris $\mathrm{HCl}(0.15 \mathrm{~g} / \mathrm{L})$, and $\left.\mathrm{pH} 7.5\right]$. For the lysis of remaining cells, this was then treated with $20 \mathrm{mg}$ of egg white lysozyme and incubated at $22{ }^{\circ} \mathrm{C}$ for $18 \mathrm{~h}$. Then the nanoparticles were separated from the lysed mixture by wash with the complete salt solution and for fur- ther characterization and application, the cleaned nanoparticles were resuspended in deionized water and stored under ambient condition. This process of purification was conducted by methods described earlier (Oremland et al., 2004).

\section{Characterization of silver nanoparticles}

Purified silver nanoparticles produced from biomass were air-dried and analyzed using SEM. SEM analysis of dried samples was performed by mounting nanoparticles on specimen stubs with double adhesive tape and coated with platinum in a sputter coater and examined under JEOL 6390 SEM JSM at $10 \mathrm{kV}$. The morphological characteristics of silver nanoparticles were analyzed using TEM. Samples for TEM analysis were prepared on carbon-coated copper TEM grids. The films on the TEM grids were allowed to stand for $2 \mathrm{~min}$, the extra solution was removed using a blotting paper, and the grid was allowed to dry prior to measurement. TEM measurements were recorded using a JEOL-JEM-1011 instrument at $80 \mathrm{kV}$.

\section{Analysis of antibacterial activity of AgNPs}

The antimicrobial activity of AgNPs synthesized by CB2 was tested against Salmonella typhi, Salmonella paratyphi, Vibrio cholerae and Staphylococcus aureus by standard well diffusion method in Muller Hinton Agar (MHA) plates (Saravanan et al., 2011). Pure cultures of bacterial pathogens were grown in Muller Hinton broth at $37{ }^{\circ} \mathrm{C}$ for $18-24 \mathrm{~h}$. The MHA plates were inoculated by swabbing these bacterial pathogens to create a confluent lawn of bacterial growth. Wells were made on the MullerHinton agar plates using a gel puncture and $40 \mu \mathrm{L}$ of the biosynthesized AgNPs solution from CB2, $40 \mu \mathrm{L}$ of AgNPs synthesized by Bacillus sp. (positive control) and $1 \mathrm{mM} \mathrm{AgNO}_{3}$ were added to separate wells. After incubation, the diameter of zone of inhibition was measured. The assays were performed in triplicates.

\section{Results and Discussion}

Water samples from Calicut beach were used as source material for the isolation of microorganisms with the potential to form silver nanoparticles. After screening for the resistance towards silver, the isolate named as CB2 showed higher resistance to silver nitrate and was selected for further investigation. The sequence data of the strain was subjected to BLAST analysis and the result of CB2 showed $100 \%$ identity to recently reported $16 \mathrm{~S}$ rDNA sequence of Ochrobactrum anthropi strain (JQ435714). The $16 \mathrm{~S}$ rDNA sequence of the isolates used in the study was also used for phylogenetic analysis and the result showed clustering of the 16S rDNA sequence of CB2 with the sequence of Ochrobactrum anthropi (Figure 1). So the isolate can be considered as strain of Ochrobactrum anthropi and 
silver nanoparticle synthesis property of this species is least explored.

The synthesis of AgNPs by the isolate CB2 was monitored by visible observation of changes in color of biomass and supernatant in the presence of $1 \mathrm{mM} \mathrm{AgNO}$ based on methods used for screening microbial isolates for silver nanoparticle synthesis (Kalimuthu et al., 2008). The observations indicated that intracellular components of the strain reduced $\mathrm{Ag}+$ ions as observed by change in color of the samples from pale yellow to brown within $24 \mathrm{~h}$ of incubation in the presence of light (supplementary data). This color change is due to the excitation of surface plasmon resonance of silver nanoparticles (Ahmad et al., 2003, Kalimuthu et al., 2008). It was also noted that the intensity of the brown color increased up to $24 \mathrm{~h}$ and was maintained throughout the $72 \mathrm{~h}$ period of observation. However, no extracellular reduction of $\mathrm{Ag}+$ ions was observed with $\mathrm{CB} 2$ in the presence of light or in the dark. This observation indi- cates that the reduction of the $\mathrm{Ag}+$ ions takes place intracellularly under visible-light irradiation. Visible light irradiation is known to have significant increasing effect on the biosynthetic rate of silver nanoparticles formation (Mokhtari et al., 2009; Wei et al., 2012, Thomas et al., 2012 b). In addition, experimental controls like heat killed biomass and supernatant of CB2 incubated in presence of silver nitrate and silver nitrate solution alone showed no color changes. Thus, this visual observation of color changes in samples containing bacterial biomass can be taken as an indication of intracellular synthesis of silver nanoparticles. Similar results were previously reported for the biomass of B. cereus and Bacillus sp. due to the reduction of aqueous silver ions to silver nanoparticles (Babu and Gunasekaran, 2009; Das et al., 2013).

The intracellular production of AgNPs in the reaction flasks were monitored by UV-Vis spectral analysis, which is a valuable tool for the preliminary characterization of

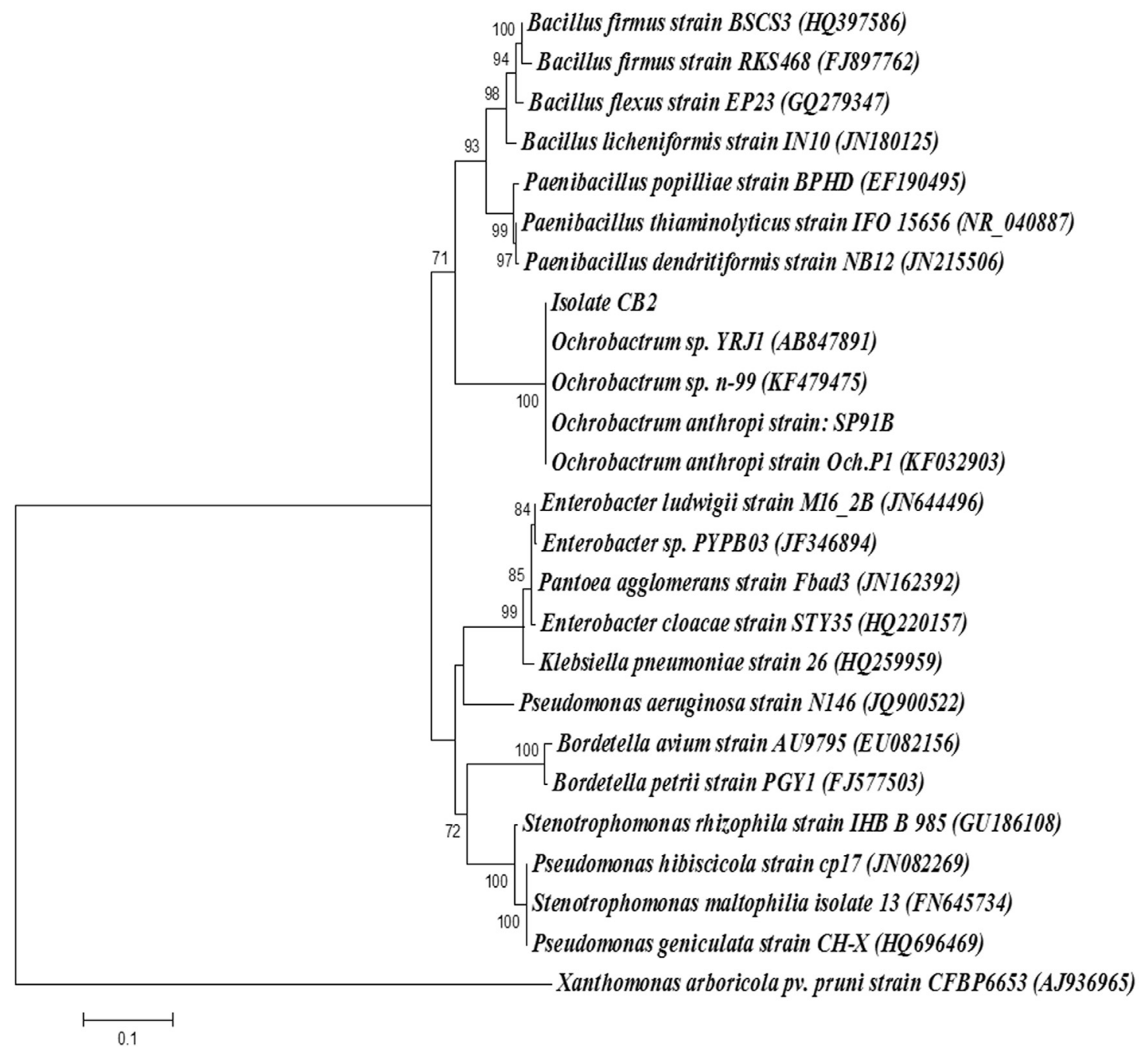

Figure 1 - The phylogenetic analysis of the 16S rDNA sequence of the marine bacterial isolate CB2 obtained in the study along with other selected sequences from database. The analysis was conducted by constructing a rooted tree [outgroup used was Xantomonas arboricola pv. pruni strain CFBP 6653 (AJ93965)] using neighbor - joining method in MEGA4. 
nanoparticles (Sastry et al., 1998). UV- visible spectra of silver nanoparticle for the test samples was obtained within $24 \mathrm{~h}$ where a strong absorption band at $450 \mathrm{~nm}$ was observed for CB2 indicating the presence of AgNPs (Figure 2). The absorption spectra of silver nanoparticles exhibited an intense absorption peak range due to its surface plasmon excitation, which describes the collective excitation of conduction electron in metal. Presence of such peak assigned to a surface plasmon resonance of silver nanoparticles was previously reported in the case of Bacillus licheniformis and Neurospora crassa (Kalimuthu et al., 2008; Longoria et al., 2011).

For further confirmation of the presence of AgNPs, the samples were subjected to purification process and purified nanoparticles were resuspended in deionized water and were used for SEM and TEM analysis. The SEM micrograph of purified nanoparticles showed the presence of silver nanoparticles at a magnification of 20,000 $\mathrm{x}$ and is shown in Figure 3 (a). Transmission electron microscopic analysis provided further insight into size and morphology of synthesized nanoparicles (Figure 3 (b)). The AgNPs were more or less spherical in shape in the TEM images with sizes ranges from $35-85 \mathrm{~nm}$. The size ranges of silver nanoparticles synthesized by the marine isolate used in the study fall closer to the size of silver nanoparticles produced by other bacteria.

The antibacterial activity of biosynthesized silver nanoparticles was investigated against both gram positive (Staphylococcus aureus) and gram negative (Salmonella typhi, Salmonella paratyphi and Vibrio cholerae) bacteria and AgNPs synthesized by CB2 (Ochrobactrum anthropi) showed excellent antibacterial activity against all tested bacterial strains at the volume of $40 \mu \mathrm{L} /$ well. In order to compare the activity of CB2, AgNPs synthesized by another Bacillus strain standardized in our laboratory (unplu-

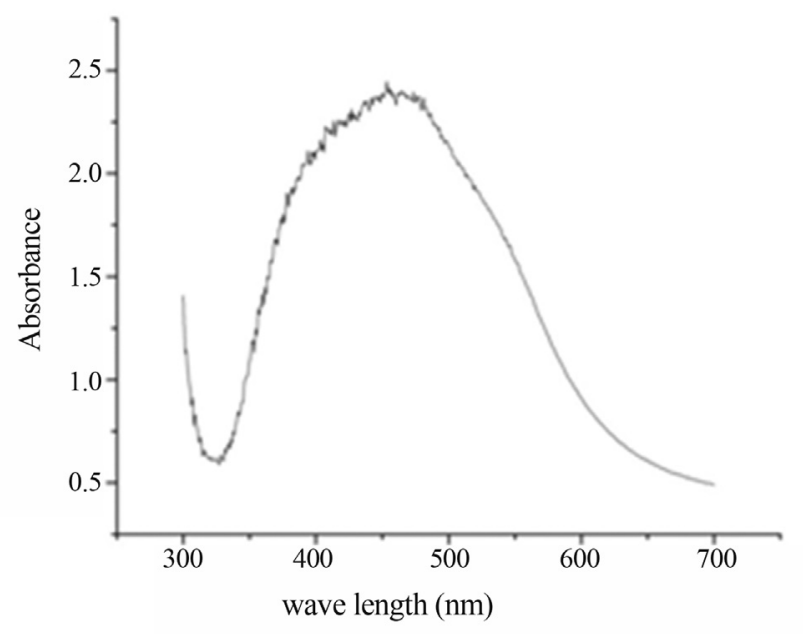

Figure 2 - The UV-Vis absorption spectrum of silver nanoparticles synthesized by Ochrobactrum sp. The absorption spectrum of silver nanoparticles exhibited a strong broad peak at $450 \mathrm{~nm}$.
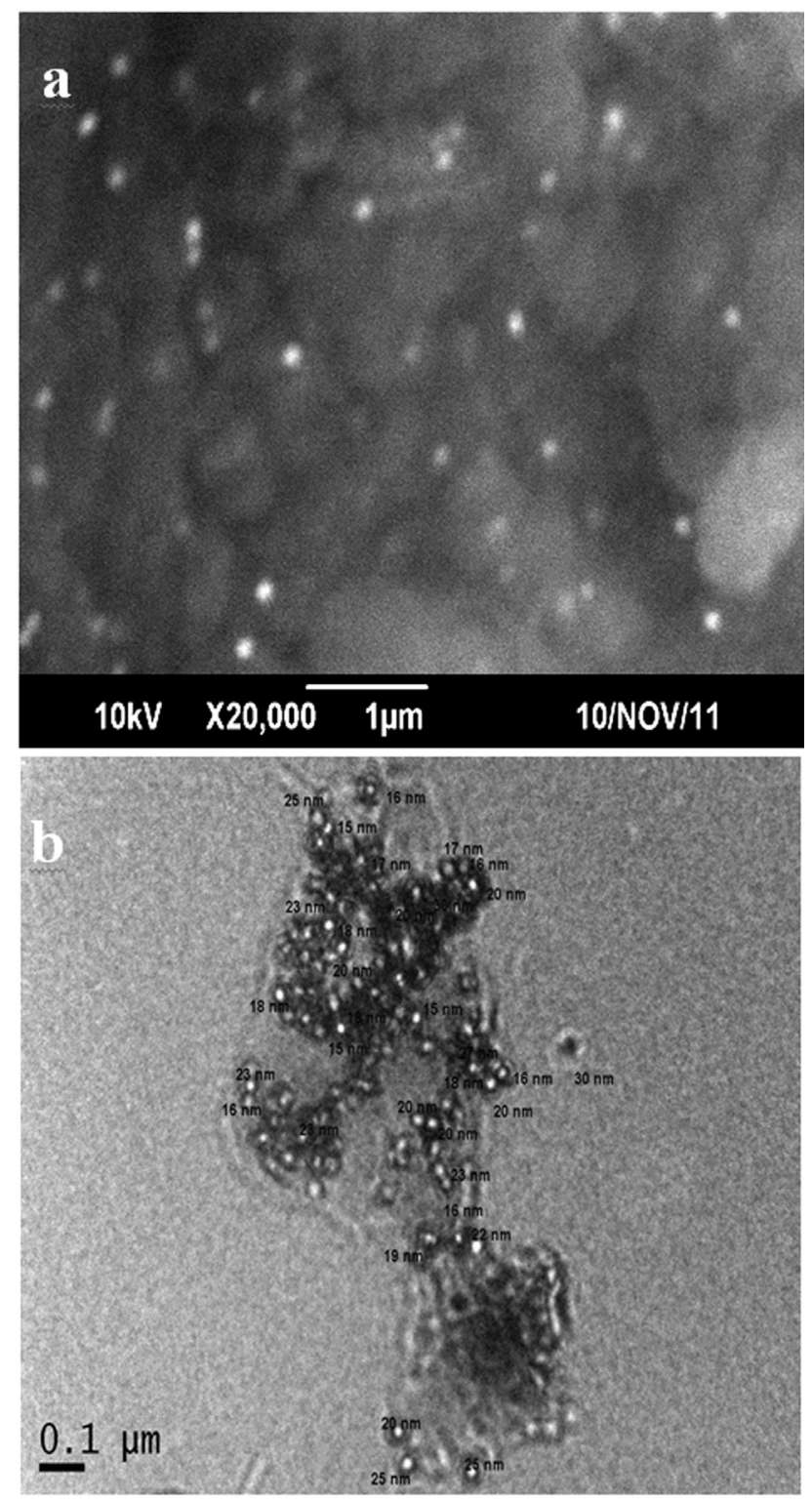

Figure 3 - Scanning Electron Microscopy (a) and Transmission electron microscopy (b) image of silver nanoparticles synthesized by Ochrobactrum sp.

blished data) was used. For Salmonella typhi, AgNPs synthesized by Bacillus sp. showed zone of inhibition of 13 $\mathrm{mm}$ and that from CB2 showed $14 \mathrm{~mm}$ zone of inhibition, for Salmonella paratyphi it was $17 \mathrm{~mm}$ for Bacillus sp. and $15 \mathrm{~mm}$ for CB2, for Vibrio cholerae it was $17 \mathrm{~mm}$ for $B a$ cillus sp. and $16 \mathrm{~mm}$ for CB2. In the case of Staphylococcus aureus AgNPs from both Bacillus sp. and CB2 showed 15 $\mathrm{mm}$ zone of inhibition (Table 1). There is no zone of inhibition around the well filled with $1 \mathrm{mM} \mathrm{AgNO}_{3}$ and this indicates the antimicrobial activity is due to biosynthesized silver nanoparticles. These findings support the previous reports of antibacterial activity of silver nanoparticles against Salmonella typhi (Saravanan et al., 2011; Sadhasivam et al., 2010), Staphylococcus aureus (Nanda 
Table 1 - Diameter of zone of inhibition by biosynthesized AgNPs against pathogenic bacteria.

\begin{tabular}{lccc}
\hline Bacteria & \multicolumn{3}{c}{ Zone of inhibition (mm) } \\
\cline { 2 - 4 } & $\begin{array}{c}\text { AgNPs synthesized by } \\
\text { Ochrobactrum anthropi }\end{array}$ & $\begin{array}{c}\text { AgNPs synthesized } \\
\text { by Bacillus sp. }\end{array}$ & $\begin{array}{c}\text { Control } \\
\left(\mathrm{AgNO}_{3}\right)\end{array}$ \\
\hline S. aureus & 15 & 15 & No zone \\
S. typhi & 14 & 13 & No zone \\
S. paratyphi & 15 & 17 & Nozone \\
V. cholerae & 16 & 17 & No zone \\
\hline
\end{tabular}

and Saravanan, 2009) and Vibrio cholerae (Renugadevi and Aswini, 2012). The bactericidal activity of silver nanoparticles is due to their small size and large surface area to volume ratio (Baker et al., 2005).

\section{Conclusion}

The nanoparticle synthesizing ability can vary among various microbial isolates. Also changes in physicochemical properties of the nanoparticles generated through diverse sources can directly affect its applications. Therefore, isolation of novel bacterial isolates from unexplored sources is a promising approach for the identification of bacteria with the potential to form nanoparticles. The marine bacterial isolate used in the study was identified as Ochrobactrum anthropi strain. This isolate was found to have the ability to form silver nanoparticles with activity against pathogens, which indicates its potential applications. This also make it sure the biological production of metallic nanoparticles as promising alternative to the known and established physical and chemical methods.

\section{Acknowledgments}

The authors gratefully acknowledge School of Chemical Sciences, Mahatma Gandhi University, Kottayam, Kerala, India for the help and support for the SEM analysis of samples and also to DBT-RGYI and DST - PURSE Programme support to Mahatma Gandhi University for the instrumentation facility.

\section{Conflict of Interest}

The authors declare that they have no conflict of interest.

\section{References}

Ahmad A, Mukherjee P, Senapati S, Mandal D, Khan MI, Kumar R (2003) Extracellular biosynthesis of silver nanoparticles using the fungus Fusarium oxysporum. Colloids Surf B 28:313-318.

Ahmad R, Minaeian S, Shahverdi HR, Jamalifar H, Nohi A (2007) Rapid synthesis of silver nanoparticles using culture supernatants of Enterobacteria: A novel biological approach. Process Bioche 42:919-923.
Ausubel FM, Brent R, Kingston RE, Moore DD, Seidman JG, Smith JA, Struhl K (1995) Short Protocols in Molecular Biology. Wiley, New York, Chp 2.4.

Babu G, Gunasekaran P (2009) Production and structural characterization of crystalline silver nanoparticles from Bacillus cereus isolate. Colloids Surf B 74:191-195.

Baker C, Pradhan A, Pakstis L, Pochan DJ, Shah SI (2005) Synthesis and antibacterial properties of silver nanoparticles. J Nanosci Nanotechnol 5:244-249.

Christopher P, Xin H, Linic S (2011) Visible-light-enhanced catalytic oxidation reactions on plasmonic silver nanostructures. Nat Chem 3:467-472.

Chun J, Goodfellow M (1995) A phylogenetic analysis of the Genus Nocardia with 16S rRNA gene sequences. Int J Syst Bacteriol 45:240-245.

Das VL, Thomas R, Varghese RT, Soniya EV, Mathew J, Radhakrishnan EK (2013) Extracellular synthesis of silver nanoparticles by the Bacillus strain CS 11 isolated from industrialized area. 3 Biotech 4: 121-126.

Elechiguerra JL, Burt JL, Morones, JR, Camacho-Bragado A, Gao X, Lara HH (2005) Interaction of silver nanoparticles with HIV-1. J Nanobiotechnol 3:6-16.

Haefeli C, Franklin C, Hardy K (1984) Plasmid-determined silver resistance in Pseudomonas stutzeri isolated from silver mine. J Bacteriol 158:389-392.

Jain N, Bhargava A, Majumdar S, Tarafdar JC, Panwar J (2011) Extracellular biosynthesis and characterization of silver nanoparticles using Aspergillus flavus NJP08: A mechanism perspective. Nanoscale 3:635-641.

Janardhanan A, Roshmi T, Rintu TV, Sonia EV, Mathew J, Radhakrishnan EK (2013) Biosynthesis of silver nanoparticles by a Bacillus sp. of marine origin. Materials Science-Poland 31(2):173-179.

Kalimuthu K, Babu RS, Venkataraman D, Bilal M, Gurunathan S (2008) Biosynthesis of silver nanocrystals by Bacillus licheniformis. Colloids Surf B 65:150-153.

Kannan N, Mukunthan KS, Balaji S (2011) A comparative study of morphology, reactivity and stability of synthesized silver nanoparticles using Bacillus subtilis and Catharanthus roseus. Colloids Surf B 86:378-383.

Klaus T, Joerger R, Olsson E, Granqvist CG (1999) Silver-based crystalline nanoparticles, microbially fabricated. Proc Natl Acad Sci USA 96:13611-13614.

Krutyakov YA, Kudrinskiy AA, Olenin AY, Lisichkin GV (2008) Synthesis and Properties of Silver Nanoparticles: Advances and Prospects. Russian Chem Re 77:233-257.

Longoria EC, Nestor ARV, Borja MA (2011).Biosynthesis of silver, gold and bimetallic nanoparticles using the filamentous fungus Neurospora crassa. Colloids Surf B 83:42-48.

Mokhtari N, Daneshpajouh S, Seyedbagheri S, Atashdehghan R, Abdi K, Sarkar S, Minaian S, Shaverdi HR, Shaverdi AR (2009) Biological synthesis of very small silver nanoparticles by culture supernatant of Klebsiella pneumonia:The effects of visible-light irradiation and the liquid mixing process. Mater Res Bull 44:1415-1421.

Nanda A, Saravanan M (2009) Biosynthesis of silver nanoparticles from Staphylococcus aureus and its antimicrobial activity against MRSA and MRSE. Nanomedicine 5:452456.

Oremland RS, Herbel MJ, Blum JS, Langley S, Beveridgem TJ, Ajayan PM, Suttot EAV, Curran S (2004) Structural and 
spectral features of selenium nanospheres produced by Serespiring bacteria. Appl Environ Microbiol 70:52-60.

Priyadarshini S, Gopinath V, Meera PN, Mubarak Ali D, Velusamy P (2013).Synthesis of anisotropic silver nanoparticles using novel strain, Bacillus flexus and its biomedical application. Coll. Surf. B 102:232-7.

Ramalingam V, Rajaram R, PremKumar C, Santhanam P, Dhinesh P, Vinothkumar S, Kaleshkumar K (2013) Biosynthesis of silver nanoparticles from deep sea bacterium Pseudomonas aeruginosa JQ989348 for antimicrobial, antibiofilm, and cytotoxic activity. J. Basic Microbiol 53:1-9.

Renugadevi K, Aswini RV (2012) Microwave irradiation assisted synthesis of silver nanoparticle using Azadirachta indica leaf extract as a reducing agent and in vitro evaluation of its antibacterial and anticancer activity. Int J Nanomat Bio 2:5-10.

Sadhasivam S, Shanmugam P, Yun K (2010) Biosynthesis of silver nanoparticles by Streptomyces hygrocopicus and antimicrobial activity against medically important pathogenic microorganisms. Colloids Surf B 81:358-362.

Saifuddin N, Wong CW, NurYasumira AA (2009) Rapid biosynthesis of silver nanoparticles using culture supernatant of bacteria with microwave irradiation. J Chem 6:61-70.

Saravanan M, Venu AK, Barik SK (2011) Rapid biosynthesis of silver nanoparticles from Bacillus megaterium (Ncim 2326)and their antibacterial activity on multi drug resistant clinical pathogens. Colloids Surf B 88:325-331.

Sastry M, Patil V, Sainkar SR (1998) Electrostatically controlled diffusion of carboxylic acid derivatized silver colloidal particles in thermally evaporated fatty amine films. J Phys Chem B 102:1404-1410.

Shahverdi AR, Minaeian S, Shahverdi HR, Jamalifar H, Nohi AA (2007) Rapid synthesis of silver nanoparticles using culture supernatants of Enterobacteriaceae: A novel biological approach. Process Biochem 42:919-923.

Shrivastava S, Bera T, Singh SK, Singh G, Ramachandrarao Dash P (2009) Characterizaion of antiplatelet properties of silver nanoparticles. ACS Nano 3:1357-1364.

Tamura K, Peterson, D, Peterson N, Stecher G, Nei M, Kumar S (2011) MEGA5: Molecular evolutionary genetics analysis using maximum likelihood, evolutionary distance, and maximum parsimony methods. Biology and evolution 28:27312739.

Thomas R, Jasim B, Mathew J, Radhakrishnan EK (2012a) Extracellular synthesis of silver nanoparticles by endophytic Bordetella sp. isolated from Piper nigrum and its antibacterial activity analysis, Nano Biomed Eng 4(4):183-187.

Thomas R, Viswan A, Mathew J, Radhakrishnan EK (2012 b) Evaluation of antibacterial activity of silver nanoparticles synthesized by a novel strain of marine Pseudomonas sp. Nano Biomed Eng 4:139-143.

Vaidhyanathan R, Gopalram S, Kaliswaralal K,Deepak V, Pandian SRK, Gurunathan, S (2010) Enhanced silver nanoparticle synthesis by optimization of nitrate reductase activity. Colloids Surf B 75I 335-341.

Wei X, Luo M, Li W, Yang L, Liang X, Xu L, Kong P, Liu H (2012) Synthesis of silver nanoparticles by solar irradiation of cell-free Bacillus amyloliquefaciens extracts and $\mathrm{AgNO}_{3}$. Bioresour Technol 103:273-278.

Zaki SMF, Kady EI, Abd-El-Haleem D (2011) Biosynthesis and structural characterization of silver nanoparticles from bacterial isolates. Mater Res Bulletin 46:1571-1576.

Zhang Z, Schwartz S, Wagner L, Miller W (2000) A greedy algorithm for aligning DNA sequences. J Comput Biol 7:203214.

\section{Supplementary Material}

Figure S1 - Visual observation of the biosynthesis of silver nanoparticles by CB2 isolate selected for the study along with control after $24 \mathrm{~h}$ of incubation. (a) supernatant with $\mathrm{AgNO}_{3}$ solution (no color change). (b) heat inactivated supernatant with $\mathrm{AgNO}_{3}$ solution (no color change). (c) bacterial biomass with $\mathrm{AgNO}_{3}$ solution (color change from pale yellow to brown). (d) heat inactivated biomass with $\mathrm{AgNO}_{3}$ solution (no color change). (e) $\mathrm{AgNO}_{3}$ solution alone (no color change).

All the content of the journal, except where otherwise noted, is licensed under a Creative Commons License CC BY-NC. 


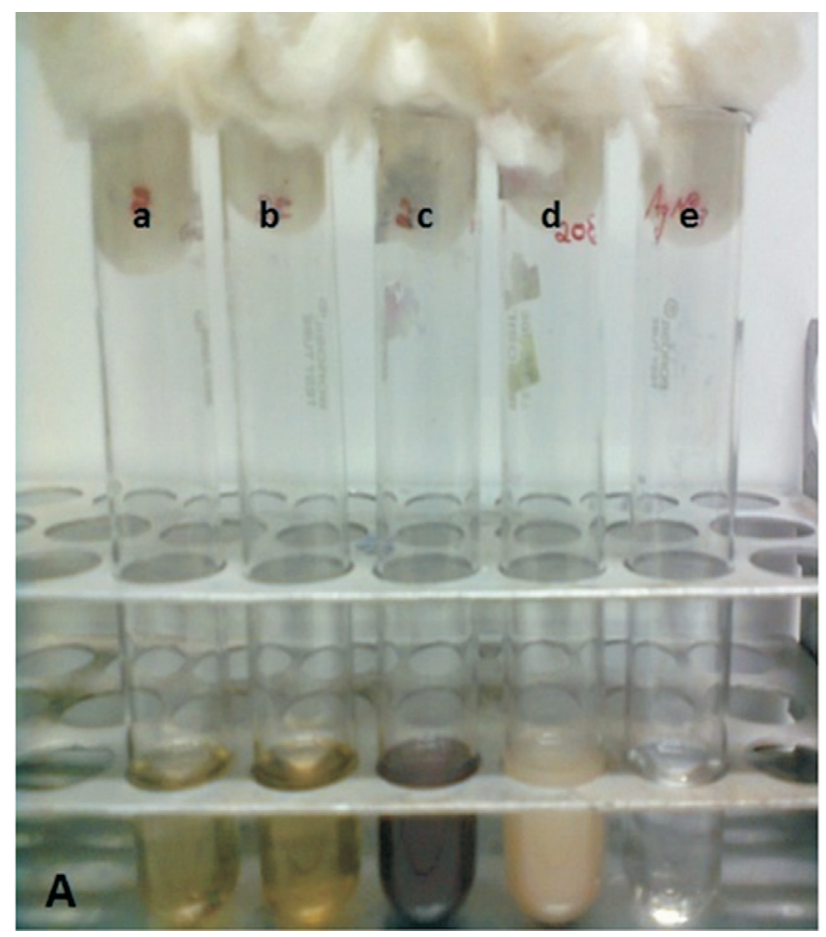

Figure S1 - Visual observation of the biosynthesis of silver nanoparticles by CB2 isolate selected for the study along with control after $24 \mathrm{~h}$ of incubation. (a) supernatant with $\mathrm{AgNO}_{3}$ solution (no color change). (b) heat inactivated supernatant with $\mathrm{AgNO}_{3}$ solution (no color change). (c) bacterial biomass with $\mathrm{AgNO}_{3}$ solution (color change from pale yellow to brown). (d) heat inactivated biomass with $\mathrm{AgNO}_{3}$ solution (no color change). (e) $\mathrm{AgNO}_{3}$ solution alone (no color change). 